\title{
As sequências didáticas como um procedimento de ensino para o gênero artigo de opinião
}

Elisete Maria de Carvalho Mesquita

elismcm@gmail.com

Universidade Federal de Uberlândia (UFU), Uberlândia, Minas Gerais, Brasil.

\section{Cleonice de Moraes Evangelista}

Leão

cleoprojovem@hotmail.com

Universidade Federal de Uberlândia

(UFU), Uberlândia, Minas Gerais, Brasil.

Dalma Flávia Barros Guimarães de Souza

dalmabarros2@hotmail.com

Universidade Federal de Uberlândia (UFU), Uberlândia, Minas Gerais, Brasil.

\section{RESUMO}

Este artigo apresenta e analisa uma proposta de trabalho para o artigo de opinião, aplicada em salas de aula do Ensino Fundamental II. Estabelecemos uma discussão a respeito de alguns temas que se relacionam com os interesses desta pesquisa, quais sejam argumentação e ensino, o gênero artigo de opinião e as sequências didáticas. Considerando a interação entre esses temas e, obedecendo aos pressupostos de Dolz, Noverraz e Schneuwly (2004), principalmente, elaboramos uma proposta para o ensino do gênero artigo de opinião, com o objetivo de levar o aluno a apropriar-se deste gênero e, consequentemente, aprimorar suas habilidades linguísticas e discursivas. Por meio dessa proposta, relacionamos a teoria com a prática pedagógica, no intuito de subsidiar o trabalho dos professores de língua portuguesa, quando o objetivo é ensinar os alunos a produzirem gêneros. Acreditamos que este trabalho possa diminuir a distância entre o que se ensina e o que o aluno utiliza em suas práticas sociais.
\end{abstract}

PALAVRAS-CHAVE: Gêneros. Argumentação. Sequências didáticas. Artigo de opinião. 
$\mathrm{RL}$

Página | 56

R. Letras, Curitiba, v. 18, n. 22, p. 55-74, jan.jun. 2016. 


\section{Introdução}

Entendendo que é essencial adotar práticas alternativas para ensino da linguagem que propiciem ao aluno o desenvolvimento de sua competência discursiva associada ao ensino do gênero, elaboramos uma sequência didática sobre o gênero artigo de opinião ${ }^{1}$, pautada nos ensinamentos de Dolz, Noverraz e Schneuwlly (2004), a fim de possibilitar ao aluno o domínio da leitura e da escrita, o que, acreditamos, pode resultar no domínio da capacidade de usar a língua em diferentes e variadas situações. Apoiamo-nos na abordagem sociodiscursiva e interacionista de Bakhtin (2003); Dolz, Noverraz e Schneuwly (2004). Trazemos também, para nosso arcabouço teórico Ferreira (2010), Abreu (2009) e OlbrechtsTyteca e Perelman (2005) no tocante à argumentação. Também tecemos algumas considerações sobre o gênero artigo de opinião, sob a ótica de Rodrigues (2005) e dos Parâmetros Curriculares Nacionais de Língua Portuguesa - PCNLP - (BRASIL, 1998), principalmente.

Visando aos objetivos propostos, estruturamos este artigo em duas partes: uma teórica e outra analítica. Na primeira, discutimos a relevância da argumentação para os estudos da linguagem e fizemos alguns comentários sobre a concepção de gênero que adotamos neste estudo. Ainda nesta seção, tecemos algumas considerações sobre o gênero artigo de opinião. Então, apresentamos o "modelo" de sequências didáticas, idealizado por Dolz, Noverraz e Schneuwly (2004), a partir do qual abordamos algumas questões teóricas e metodológicas sobre o ensino de gêneros, mais especificamente, sobre o artigo de opinião. $\mathrm{Na}$ segunda parte, descrevemos e analisamos a sequência didática por nós elaborada. Por fim, apresentamos as considerações finais e as referências que subsidiaram este trabalho.

\section{Argumentar é preciso}

Para Bakhtin (2003, p. 261), "todos os diversos campos da atividade humana estão ligados ao uso da linguagem", ou seja, a linguagem é essencial para as práticas sociais em que o ser humano está inserido. Sabendo que não existem discursos neutros, já que todos os discursos têm propósito(s) comunicativo(s), podemos afirmar que a argumentação é um dos principais recursos da linguagem. Desta forma, utilizar a argumentação de maneira adequada pode fazer com que tenhamos mais êxito em nossas vidas, rendamos mais e sejamos mais felizes. (ABREU, 2009).

Nessa mesma linha de entendimento, os PCNLP (BRASIL, 1998) preceituam o desenvolvimento da argumentação no ensino da língua/linguagem, ressaltando que a linguagem verbal "possibilita não só a representação e a regulação do pensamento e da ação, próprios e alheios, mas, também, comunicar ideais, pensamentos e intenções de diversas naturezas e, desse modo, influenciar o outro e estabelecer relações interpessoais anteriormente inexistentes". (BRASIL, 1998, p. 22).

É necessário, então, que definamos o que vem a ser argumentar. Segundo Abreu (2009), para o senso comum, argumentar é vencer alguém, forçá-lo a submeter-se a nossa vontade. Esse autor explica, entretanto, que essa definição é equivocada, uma vez que ela se atrela direta e inequivocadamente a uma definição de guerra. Argumentar, na verdade, para Abreu é "saber integrar-se ao universo 
do outro. É também obter aquilo que queremos, mas de modo cooperativo e construtivo, traduzindo nossa verdade dentro da verdade do outro" (ABREU, 2009, p. 02). Nesse mesmo sentido, Olbrechts-Tyteca e Perelman afirmam que "consentir na discussão é aceitar colocar-se do ponto de vista do interlocutor, é só se prender ao que ele admite e não se prevalecer de suas próprias crenças". (OLBRECHTS-TYTECA; PERELMAN 2005, p. 61-62).

Abreu (2009, p. 08) afirma que "argumentar é a arte de convencer e persuadir". Dessa forma, para que compreendamos melhor o conceito de argumentação, necessário se faz entendermos o que vem a ser convencer e persuadir.

\footnotetext{
Convencer é saber gerenciar informação, é falar à razão do outro, demonstrando, provando. Etimologicamente, significa vencer junto com o outro (com + vencer) e não contra o outro. Persuadir é saber gerenciar relação, é falar à emoção do outro. A origem dessa palavra está ligada à preposição per, "por meio de" e à Suada, deusa romana da persuasão. Significava "fazer algo por meio do auxílio divino". Mas em que convencer se diferencia de persuadir? Convencer é construir algo no campo das ideias. Quando convencemos alguém, esse alguém passa a pensar como nós. Persuadir é construir no terreno das emoções, é sensibilizar o outro para agir. Quando persuadimos alguém, esse alguém realiza algo que desejamos que ele realize. (ABREU, 2009, p. 08)
}

Ferreira (2010), comungando das ideias de Abreu (2009) no que tange à distinção do ato de persuadir e convencer, esclarece que o primeiro está mais relacionado à exploração do lado emocional e o segundo está associado à razão. $\mathrm{E}$ acrescenta que o discurso retórico está mais relacionado à persuasão, já que objetiva persuadir um auditório que se encontra diante de uma questão polêmica.

Verificamos, então, que a eficiência de uma argumentação está relacionada ao auditório e a sua natureza. Mas, afinal, o que é o auditório? Para Ferreira (2010, p. 22) o auditório é "o leitor ou ouvinte de um ato retórico". Já Abreu (2009, p.16) entende que o "auditório é um conjunto de pessoas que queremos convencer e persuadir". Para Olbrechts-Tyteca e Perelman (2005, p. 22) auditório é "o conjunto daqueles que o orador quer influenciar", tendo em vista que "cada orador pensa de uma forma mais ou menos consciente, naqueles que procura persuadir e que constituem o auditório ao qual se dirigem seus discursos".

Embora esses pontos de vista sejam um tanto distintos, podemos dizer que eles se complementam e nos levam ao entendimento de que o tamanho de um auditório varia muito, podendo ser do tamanho de um país ou formado por uma única pessoa. Nem sempre o interlocutor é o auditório, por exemplo, "um repórter que entrevista você não é seu auditório, é apenas seu interlocutor. $O$ auditório são os leitores do jornal ou os telespectadores em suas casas". (ABREU, 2009, p.15). Assim sendo, há dois tipos de auditório: o auditório universal e o auditório particular. O primeiro representa "um conjunto de pessoas sobre as quais não temos controle de variáveis". (ABREU, 2009, p. 15). Por exemplo, o público que assiste a um programa de televisão. A universalidade do auditório pode ser abstrata ou concreta. Ela será abstrata quando referir-se à humanidade inteira, ou seja, a todos que podem receber a mensagem. Já a abstrata refere-se àqueles que receberão, de fato, a mensagem. cujas variáveis controlamos", ou seja, pode ser tanto um grupo específico de 
pessoas, como também uma pessoa específica. É importante ressaltar que "O conhecimento daqueles que se pretende conquistar é, pois, uma condição prévia de qualquer argumentação eficaz." (OLBRECHTS-TYTECA; PERELMAN, 2005, p. 23). Dessa forma, o orador precisa adaptar-se ao auditório, já que é ele que determina a qualidade da argumentação e o comportamento dos oradores.

Para que a argumentação seja eficaz, além do conhecimento do auditório, é necessário recorrer à persuasão, a partir da qual é possível gerenciar de forma positiva o relacionamento com o outro. Para tanto, é imprescindível educar nossa sensibilidade para os valores (éticos) do outro, de modo que gerenciemos suas emoções e valores, que estão ligados à multiplicidade de grupos e de emoções. Dessa forma, para persuadir devemos conhecer os verdadeiros valores do interlocutor "quando dizemos que os homens são iguais porque são filhos de um mesmo Deus, parecemos estear-nos num valor concreto para encontrar um valor abstrato, o da igualdade" (OLBRECHTS-TYTECA; PERELMAN, 2005, p. 88).

Ainda segundo Olbrechts-Tyteca e Perelman (2005), o auditório é caracterizado não pelos valores que possui, mas pelo grau de importância que ele dá a esses valores, ou seja, há uma hierarquia de valores, pois alguns são "mais importantes do ponto de vista da estrutura de uma argumentação do que os próprios valores" (p. 92). Essa hierarquia de valores depende da cultura, das ideologias e da história pessoal do interlocutor, de modo que a exploração dessa hierarquia é imprescindível no processo persuasivo.

Argumentar, então, não é tentar impor nossa razão, nossa força, nossos desejos ao(s) outro(s). "Argumentar é, em primeiro lugar, convencer, ou seja, vencer junto com o outro, caminhando ao seu lado, utilizando, com ética, as técnicas argumentativas, para remover os obstáculos que impedem o consenso" (ABREU, 2009, p. 41).

Considerando que a argumentação é de grande importância para o desenvolvimento da competência discursiva dos alunos, entendemos, tal qual Abreu (2009), que é necessário nos tornarmos persuasivos no campo da educação, persuadindo os alunos a manterem a disciplina necessária para o estudo, como também e, principalmente, ensinando-os a serem persuasivos nos momentos em que deles a sociedade exigir. Tendo em vista que a argumentação é muito relevante para que os alunos se tornem cidadãos críticos e reflexivos, cabe à escola ensiná-los a argumentar.

Os PCNLP também discorrem sobre a importância da escola e a mediação do professor no tocante ao ensino da argumentação. Para esses documentos, cabe a ambos instaurarem o espaço para reflexão de discursos que apresentem ao aluno, possibilidades de análise crítica e reflexiva sobre seu próprio discurso, como: valores, preconceitos e intenções, o que contribuirá para o desenvolvimento de sua competência discursiva.

Trata-se de instaurar um espaço de reflexão em que seja possibilitado o contato efetivo de diferentes opiniões, onde a divergência seja explicitada e o conflito possa emergir; um espaço em que o diferente não seja nem melhor nem pior, mas apenas diferente, e que, por isso mesmo, precise ser considerado pelas possibilidades de reinterpretação do real que apresenta; um espaço em que seja possível compreender a diferença como constitutiva dos sujeitos (BRASIL, 1998 p. 48). 
Considerando a importância de se contribuir para que os alunos aprendam a argumentar, acreditamos que a escola deva promover o ensino de gêneros discursivos que explorem a argumentação. Razão pela qual, apresentamos a seguir, a concepção de gênero por nós adotada nesta proposta.

\section{Sobre os gêneros: uma breve discussão}

No contexto atual, observamos um crescente estudo sobre os gêneros em suas perspectivas teóricas e no tocante ao ensino de língua materna. Parte desse crescimento se deve à publicação dos PCNLP (BRASIL, 1998), que representam relevante referencial para o ensino de língua portuguesa no Brasil. Esses documentos preceituam o ensino de gêneros por meio da seguinte concepção bakhtiniana: "os textos organizam-se sempre dentro de certas restrições de natureza temática, composicional e estilística, que os caracterizam como pertencentes a este ou aquele gênero" (BRASIL, 1998, p. 23).

Nesta mesma tendência, adotamos para este estudo a noção de gêneros na perspectiva de Bakhtin, que define os gêneros como "tipos relativamente estáveis de enunciados" (2003, p. 262), que se realizam em um domínio de prática social, em que os sujeitos têm atitude responsiva ativa, concordam, discordam, completam ou usam, alternadamente, o discurso do outro. Essa alternância dos sujeitos do discurso é que possibilita os limites de cada enunciado "nos diversos campos da atividade humana e da vida" (2003, p.275) dependendo das variadas formas que assumem cada situação de comunicação, num dado momento histórico da sociedade e/ou linguagem.

Esse teórico defende a ligação da atividade humana com a situação social de interação, projeto de dizer e enunciados. Em relação aos enunciados, eles são construídos de palavras, frases, orações, mas isso não garante unidades da língua transformar-se em unidade da comunicação discursiva. É preciso levar em conta a conclusibilidade específica do enunciado, que "é uma espécie de aspecto interno da alternância dos sujeitos do discurso; essa alternância pode ocorrer precisamente porque o falante disse (ou escreveu) tudo o que quis dizer em dado momento ou sob dadas condições". (BAKHTIN, 2003, p. 280).

Bakhtin ainda nos apresenta três elementos genéricos que se fundem na realização dos enunciados, isto é, três dimensões constitutivas do gênero, quais sejam: conteúdo temático, construção composicional e estilo. Podemos compreender a primeira como os sentidos e os conteúdos abordados nos enunciados em suas realidades socioculturais. Já a segunda refere-se à própria estrutura formal do gênero, sua apresentação e organização. A terceira dimensão contempla os recursos lexicais, bem como os fraseológicos e os gramaticais ligados ao enunciado e, simultaneamente, à estrutura de composicional e ao conteúdo temático (DIAS, 2012). Neste sentido, para se analisar estas dimensões, é necessário considerar as condições sócio-históricas atreladas ao momento de produção dos enunciados.

Dentre as várias perspectivas de análise dos gêneros, não podemos deixar de considerar a proposta de Schneuwly e Dolz (2004), que entendem o gênero como um megainstrumento ou instrumento que veicula ações de linguagens situadas e se definem por três dimensões essenciais, ancorados na perspectiva bakhtiniana: “1) os conteúdos que são (que se tornam) dizíveis por meio dele; 2) a estrutura 
(comunicativa) particular dos textos pertencentes ao gênero; 3) as configurações específicas das unidades de linguagem" (SCHNEUWLY; DOLZ 2004, p. 52). Acreditamos que o diálogo com esses autores, principalmente, possa contribuir para que o objetivo desta pesquisa seja alcançado.

Para desenvolver a argumentação dos alunos na escola, e, consequentemente, desenvolver sua competência discursiva, essencial para o exercício da cidadania. Nesse estudo, optamos trabalhar com o gênero artigo de opinião. A escolha desse gênero se justifica pelo fato de entendermos que ele é predominantemente argumentativo, o que pode facilitar o processo de compreensão da íntima relação existente entre produzir textos e argumentar.

\section{O gênero artigo de opinião e suas particularidades}

Sabemos que o domínio da linguagem, por possibilitar a plena participação social, é essencial para a atividade humana. Os PCNLP definem a natureza da linguagem e sua relação com ensino da seguinte forma: "Linguagem aqui se entende, no fundamental, como ação interindividual orientada por uma finalidade específica, um processo de interlocução que se realiza nas práticas sociais existentes nos diferentes grupos de uma sociedade, nos distintos momentos de sua história." (BRASIL, 1998, p. 20). Os PCNLP, então, nos apresentam condições para o tratamento do gênero enquanto objeto de ensino em língua portuguesa. Primeiramente, instruem que "toda educação comprometida com o exercício da cidadania precisa criar condições para que o aluno possa desenvolver sua competência discursiva." (BRASIL, 1998, p. 20). Compreendemos, como Dias et al (2011, p. 153), que a competência discursiva refere-se à "capacidade que os usuários da língua devem ter para escolher o gênero mais adequado aos seus propósitos, na prática de produção de textos, e de, na prática de leitura, reconhecer o gênero em evidência, suas especificidades e a prática social a qual ele está vinculado." Os PCNLP também defendem esse mesmo ponto de vista:

\footnotetext{
Um dos aspectos da competência discursiva é o sujeito ser capaz de utilizar a língua de modo variado, para produzir diferentes efeitos de sentido e adequar o texto a diferentes situações de interlocução oral e escrita. É o que aqui se chama de competência linguística e estilística. Isso, por um lado, coloca em evidência as virtualidades das línguas humanas: o fato é que são instrumentos flexíveis que permitem referir o mundo de diferentes formas e perspectivas; por outro lado, adverte contra uma concepção de língua como sistema homogêneo, dominado ativa e passivamente por toda a comunidade que o utiliza. (BRASIL, 1998, p. 23)
}

Compreendemos que a competência discursiva se refere a um tipo de conhecimento mais abrangente, pois envolve todas as capacidades comunicativas. Além disso, é a capacidade de não só compreender os discursos, mas também a capacidade de se adequar às diferentes situações comunicativas. Para o desenvolvimento da competência discursiva, essencial para o exercício da cidadania, os PCNLP afirmam que a escola deve "organizar as atividades curriculares relativas ao ensino-aprendizagem da língua e da linguagem" (BRASIL, 1998, p. 23). Para tanto adotam a utilização do texto enquanto objeto de ensino, por meio do qual há a possibilidade de se trabalhar com a diversidade de gêneros em língua portuguesa no Ensino Fundamental. O desenvolvimento dessa capacidade poderá resultar na melhoria da qualidade da educação básica. Assim, 
optamos pelo estudo do gênero artigo de opinião, por entendermos que ele pode propiciar ao aluno o desenvolvimento da capacidade argumentativa, que é tão latente na fase da adolescência.

O artigo de opinião se enquadra no domínio social de discussão de problemas sociais controversos, desenvolvida na modalidade argumentar ${ }^{2}$, trazendo aos alunos a capacidade de dominar a linguagem no tocante à sustentação, refutação e negociação de tomadas de posição. Esse posicionamento é ratificado por Boff, Köche e Marinello $(2009$, p. 03) ao aduzirem que o artigo de opinião "pertence à ordem do argumentar, uma vez que o sujeito enunciador assume uma posição a respeito de um assunto polêmico e a defende". Já os PCNLP (BRASIL, 1998), ao apresentarem os conteúdos referentes ao terceiro e quarto ciclos do Ensino Fundamental, elencam o gênero artigo como sendo gênero de imprensa, inserido na modalidade de leitura e escrita, ou seja, de acordo com os PCNLP, esse gênero deve ser privilegiado na escola.

A principal função do artigo de opinião é convencer o outro, é influenciá-lo por meio de sua argumentação, transformando os seus valores por meio de uma determinada posição assumida pelo autor; refutando, assim, as possíveis opiniões divergentes. Dessa forma, para se produzir um artigo de opinião, é imprescindível que haja uma questão polêmica a ser discutida, ou seja, uma questão controversa referente a um tema específico, debatido em determinados círculos sociais (BRÄNKLING, 2000).

Segundo Cunha (2010), o artigo de opinião é formado não só por outros discursos sobre os fatos comentados, mas também, por antecipações das objeções do leitor. Assim, faz o leitor aderir ao seu ponto de vista, criticando as posições com as quais mantém uma relação de conflito. Os discursos, no artigo de opinião, podem ser explícitos ou não. De modo que, traz ao sujeito a construção de um trabalho incessante com o já dito.

Segundo Rodrigues (2005),

O artigo apresenta certos traços em comum com os outros gêneros jornalísticos, tais como: a interação autor/leitor não acontece no mesmo espaço e tempo físicos; também não ocorre "de pessoa a pessoa", mas é "mediada ideologicamente" pela esfera do jornalismo; eles têm determinada periodicidade (diária, semanal) e "validade" prevista (um curso de vinte quatro horas nos jornais diários; de uma semana, etc.). (RODRIGUES, 2005, p. 170)

Tratando especificamente dos traços deste gênero, a mesma autora afirma que há na comunicação jornalística, um espaço que "filtra, interpreta (impõe um acento de valor) e põe em evidência os fatos, acontecimentos, saberes, opiniões etc. que farão parte do universo temático-discursivo jornalístico." (RODRIGUES, 2005, p. 171). Esse espaço refere-se aos cadernos e seções do jornal, nos quais se verificam o tema, o estilo e a construção composicional do gênero. $\mathrm{O}$ artigo "se situa na seção Opinião, elemento constitutivo do gênero, pois é o lugar de sua ancoragem ideológica, delimitando a que parte do universo temático do jornalismo ele se refere, qual o seu horizonte temático, sua finalidade da interação". (p.171) Assim, faz um juízo de valor a respeito dos acontecimentos da esfera social presentes na notícia jornalística. Por isso, "é um dos gêneros onde os participantes da interação se reconhecem e assumem esse trabalho avaliativo do autor". (RODRIGUES, 2005, p. 171). 
Não poderíamos nos esquecer de tratar do interlocutor do artigo de opinião, pois sabemos que geralmente este gênero vem publicado em jornal, espaço voltado às diversas camadas sociais, por publicarem assuntos atuais comuns a todos. Todavia, de acordo com Rodrigues (2005), esse gênero é pouco encontrado em jornais voltados para classes populares. Dessa forma, podemos inferir que o artigo de opinião é reservado a um público pertencente a classes mais altas da sociedade. Neste sentido, é imprescindível que nós professores apresentemos o referido gênero a nossos alunos, a fim de que eles ampliem sua linguagem e participem mais ativamente da sociedade da qual fazem parte.

No que tange à autoria, Rodrigues (2005) nos ensina que esta não se alude à pessoa física, mas "à posição de autoria inscrita no próprio gênero; refere-se a uma 'postura de autor' com sua responsabilidade discursiva". Geralmente, trata-se da figura social pública falando de acontecimentos sociais atuais em sua área de atuação. É importante ressaltarmos que a notoriedade social e profissional do articulista é o que traz credibilidade ao seu discurso, resultando na formação ou modificação de opinião. Assim, o articulista "incorpora a aura da competência sociodiscursiva" por incorporar o ethos da competência social e discursiva resultante "de sua circulação na mídia e pela função social exercida". Ou seja, a relevância do articulista traz ao artigo de opinião um argumento de autoridade. (RODRIGUES, 2005, p. 171-172).

Ademais, o artigo apresenta um discurso dialogizador, na medida em que o articulista argumenta com o objetivo de convencer e persuadir o leitor, por meio de conhecimentos comuns ou ideológicos que o conquistem e o levem à posição de coautor.

Como a finalidade discursiva do artigo não se orienta especificamente para apresentação dos acontecimentos sociais em sim (como no gênero notícia), mas para a sua apreciação, eles se constituem como um fundo discursivo dialogizador, considerado de domínio do leitor, a partir do qual o articulista constrói seu acento de valor, e que o leitor precisa reconstruir na sua reaçãoresposta. (RODRIGUES, 2005, p. 173).

Assim, o conteúdo temático do artigo de opinião se encontra na articulação entre a apreciação dos acontecimentos sociais e a questão do posicionamento externo ao jornal. Além disso, o autor mantém relações dialógicas com enunciados ditos anteriormente ao incorporar diferentes vozes e seus acentos de valor, seja para validá-las concordando com elas "movimento dialógico de assimilação", seja para desqualificá-las refutando-as "movimento dialógico de distanciamento." (RODRIGUES, 2005, p. 174). As relações dialógicas também podem ser evidenciadas no tocante aos aspectos estilístico-composicionais, tendo em vista que são marcadas pela escolha de palavras, verbos, expressões avaliativas, operadores argumentativos, aspas, etc., como recursos argumentativos, a fim de persuadir e convencer o leitor e com ele estabelecer um diálogo.

Em virtude do exposto, podemos dizer que o trabalho com o artigo de opinião, desenvolvido com a ajuda da sequência didática, é de suma importância para o aprimoramento da competência discursiva dos alunos. Por acreditarmos que o procedimento da sequência didática constitui uma metodologia eficiente para a apropriação desse e de outros gêneros é que discorremos sobre ele no tópico que se segue. 


\section{As sequências didáticas como um procedimento de ensino de gêneros em língua portuguesa}

As sequências didáticas constituem uma proposta teórica e metodológica do ensino de língua materna construída em torno de gêneros. Essa proposta foi desenvolvida por Dolz, Noverraz e Schneuwly (2004), que a definem da seguinte forma: "conjunto de atividades escolares organizadas, de maneira sistemática, em torno de um gênero textual oral ou escrito", com intuito de "dar acesso aos alunos a práticas de linguagem novas ou dificilmente domináveis" (DOLZ; NOVERRAZ; SCHNEUWLY, 2004, p. 97 - 98).

Dolz, Noverraz e Schneuwly (2004) apontam, de forma clara, que uma sequência didática tem por finalidade "ajudar o aluno a dominar melhor um gênero, permitindo, assim, escrever ou falar de maneira mais adequada numa dada situação de comunicação". (p. 97) Assim, propõem um ensino da língua mediado pelos gêneros, pelo fato de que os alunos gradualmente se apropriam dos conhecimentos dos gêneros, e simultaneamente internalizam as práticas de linguagem, que resultam na compreensão da língua.

Para os autores da escola de Genebra, a estrutura de base de uma sequência didática é um processo formado por quatro etapas, quais sejam: apresentação da situação, produção inicial, módulos e produção final. Essa estrutura é operacionalizada pela situação de produção, pelos objetivos e pelas tarefas propostas durante a realização da sequência didática.

A apresentação da situação é a primeira etapa de uma sequência didática e se constitui em duas dimensões, sendo que a primeira é "a do projeto coletivo de produção de um gênero oral ou escrito" (DOLZ, NOVERRAZ; SCHNEUWLY, 2004, p. 99) e a segunda é a dimensão dos conteúdos. Na primeira dimensão se definirá qual gênero será produzido, para quem o texto será destinado, que forma ele tomará, quem serão os participantes da produção do texto, etc. A dimensão dos conteúdos se constitui na discussão do tema e na exposição de textos do mesmo gênero a ser produzido.

A segunda etapa refere-se à produção inicial, que nada mais é do que a tentativa do aluno em produzir seu primeiro texto oral ou escrito do gênero solicitado. Essa produção se configura como um diagnóstico do conhecimento prévio dos alunos, que é pertinente tanto para os alunos (conscientização dos problemas que possuem) quanto para o professor (percepção das capacidades e deficiências dos alunos).

Os módulos ou oficinas constituem a terceira etapa da sequência didática, e o seu desenvolvimento é pautado na superação dos problemas diagnosticados na produção inicial. Por isso, não possui uma forma fixa; podendo, assim, ser adaptados, de acordo com a(s) necessidade(s) dos alunos.

Portanto, para que os alunos consigam resolver gradativamente seus problemas específicos com cada gênero e com a língua materna, o professor deverá avaliar os problemas encontrados na produção inicial, selecioná-los e produzir atividades e estratégias para sanar as falhas dos alunos, para que enfim, possam elaborar uma linguagem pertinente ao gênero proposto. Assim, para subsidiar o conhecimento do aluno, é necessário que esta ampliação feita pelo 
Trabalhar problemas de níveis diferentes; b) Variar as atividades e os exercícios; c) Capitalizar as aquisições.

A produção final é a quarta e última etapa. É ela que encerra a sequência didática, oferecendo ao aluno, segundo Dolz; Noverraz; Schneuwly (2004, p. 107) "a possibilidade de pôr em prática as noções e os instrumentos elaborados separadamente nos módulos" após a análise da produção inicial. Ademais, a produção final é um instrumento que o professor pode utilizar para avaliar a evolução dos alunos em relação à primeira produção. Deste modo, os alunos se apropriam das peculiaridades do gênero e da língua materna e vão superando gradativamente suas dificuldades, podendo enfim, utilizar adequadamente a linguagem oral e escrita em suas práticas sociais.

Em virtude do exposto, concluímos que os ensinamentos dos pesquisadores da escola de Genebra, no que se refere às sequências didáticas, são de grande valor para o trabalho com os gêneros em sala de aula, tendo em vista que elencam etapas sequenciais e progressivas da aula, que auxiliam o aluno no domínio não só de um determinado gênero, mas também na prática da linguagem, em suas múltiplas facetas.

\section{Uma proposta de sequência didática para o gênero artigo de opinião}

Feitas as discussões teóricas, dedicar-nos-emos à apresentação do resumo da sequência didática que elaboramos e aplicamos em sala de aula, a partir da proposta dos estudiosos da escola de Genebra, como metodologia para o ensino do gênero artigo de opinião. Ressaltamos a importância de se trabalhar atividades direcionadas para esse gênero em sala de aula, já que ele envolve a argumentação e seu ensino. [É importante esclarecer que esta sequência teve como série-alvo o 9o ano do ensino fundamental do Colégio Estadual Oscar Ribeiro da Cunha, localizado no município de Rio Verde - Goiás, no qual trabalhamos com duas turmas, totalizando 60 alunos, durante o mês de setembro do ano letivo de 2015.]

Sabemos que a finalidade fundamental da sequência didática é ajudar o aluno a dominar um determinado gênero, melhorando sua linguagem em uma dada situação de comunicação. Além disso, sabemos que sua aplicação consiste em momentos distintos e articulados entre si, que objetivam não só a aprendizagem progressiva do gênero artigo de opinião, bem como o desenvolvimento da argumentação dos alunos. Para tanto utilizamos como recursos alguns vídeos, textos diversificados e atividades sistematizadas. Passemos, então, à exposição de cada um desses momentos.

\section{Primeiro momento - Apresentação da situação}

1a aula: Os alunos assistiram ao vídeo do Daniel Alves comendo uma banana no campo de futebol, enquanto sofria uma ação racista por um torcedor ${ }^{3}$ e uma entrevista da torcedora do Grêmio que chamou o jogador de Aranha de macaco ${ }^{4}$. Em seguida, dissemos aos alunos: Vamos estudar, a partir de hoje, o gênero artigo de opinião, com o objetivo de escrevermos um artigo de opinião sobre o que pensamos da atitude de pessoas que sofrem ou têm atitudes racistas no futebol, para publicá-lo (blog, site ou mural da escola). A seguir, solicitamos aos alunos que lessem, em grupos, artigos de opinião presentes em revistas, jornais, blogs e sites de renome, sobre o tema racismo no futebol e apresentassem oralmente à turma. 
Em seguida, os alunos conversaram sobre os meios de circulação, produção e finalidade desses artigos. Depois, tentaram conceituar o gênero.

2a aula: - Reconhecer as principais diferenças entre o texto argumentativo e o texto informativo. Promovemos uma conversa dialogada com os alunos sobre o gênero notícia. Retomamos os jornais, revistas, blogs e sites e desta vez para procurar notícias que estivessem relacionadas ao artigo selecionado pelo seu grupo, na aula anterior. Para enfim, responderem a alguns questionamentos sobre características do gênero notícia.

\section{Segundo momento - Produção inicial}

3a aula: Solicitamos aos alunos a produção de um artigo de opinião com a seguinte questão polêmica "O que podemos fazer para diminuir atitudes racistas no futebol?" a fim de diagnosticar o conhecimento prévio dos alunos. Apresentamos a situação de produção aos alunos, quais sejam: Quem escreveria o texto, para quem, com que finalidade, quem leria o texto. $O$ texto foi corrigido e arquivado por nós professoras.

- Terceiro momento - Módulos. Aplicamos os módulos abaixo, a partir dos problemas diagnosticados na produção inicial. Além disso, fomos construindo um cartaz com os alunos acrescentando cada aspecto trabalhado nos módulos, de forma gradativa.

Módulo 01: 4a aula - Primeira atividade: contexto da produção textual Leitura do artigo de opinião "As Escolhas da Vida"5, de Walter Somanti Hassin e identificação de: autor/papel social, interlocutores, época e meio de circulação, finalidade.

Módulo 02: 5a aula - Diferenciar fato de opinião. Ler o conceito no texto "Verdade x opinião" ${ }^{6}$, de William Cereja e Thereza Cochar e discutir com os alunos a diferença entra fato e opinião. Em seguida, ler o artigo de opinião "Banana para o racismo"7, de Luiz Flávio Gomes. Após leitura detalhada sublinhe de azul o que for fato, e de vermelho, o que for opinião.

Módulo 03: 6a aula - Identificar as questões polêmicas e o posicionamento do autor. Leitura e interpretação do artigo de opinião "As escolhas de uma vida" ${ }^{8}$, de Pedro Bial e responder a alguns questionamentos sobre a questão polêmica do texto e o posicionamento do autor.

Módulo 04: 7ạ aula - Diferenciar tipos de argumentos; Construir argumentos de causa/ consequência e argumentos de exemplificação. (Optamos trabalhar com apenas estes, mas o professor poderá introduzir outros tipos de argumentos, se achar pertinente). Prática de oralidade: Dividir os alunos em dois grupos e propor um debate. Um grupo defende os artistas que apoiaram o jogador Daniel Alves com a hashtag "\#SomosTodosMacacos" e o outro grupo defende os artistas que foram contra. Entregar as imagens selecionadas e direcionadas a cada grupo. Os alunos devem defender suas ideias observando a construção dos argumentos de causa/ consequência e argumentos de exemplificação. (Para esta atividade os alunos podem pesquisar sobre o tema).

É importante que antes de se iniciar o debate oral, o professor explique aos alunos a diferença entre convencer e persuadir. Tendo em vista que neste momento, os alunos mais do que convencer, devem persuadir o outro grupo de que seus argumentos são os melhores. 
Grupo A: A favor da hashtag \#SOMOSTODOSMACACOS\#

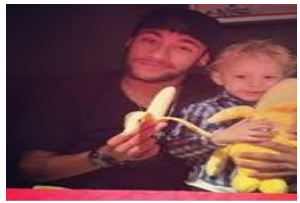

Grupo B: Contra a hashtag

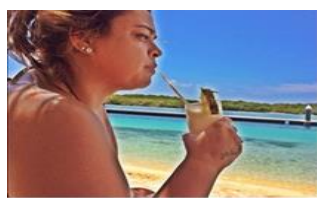

"Não sou macaca, sou negra com muito orgulho!" Racismo é crime, cadeia neles!
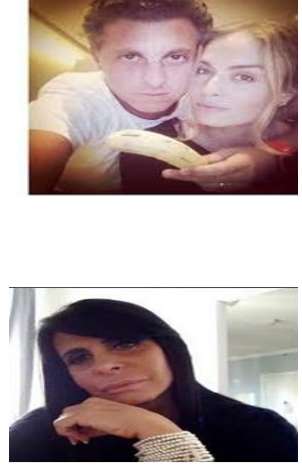

"Na hora chamar o Richarlysson de "viado" ninguém liga e acha graça, mas quando chamam o Daniel Alves de "macaco" todo mundo se dói. Preconceito é preconceito de qualquer jeito, quero ver usarem a hashtag \#SomosTodosViados porque ser macaco é fácil...". ${ }^{9}$

Prática de leitura: após o debate, retomar os artigos lidos em aulas anteriores e identificar os tipos de argumentos presentes em cada artigo de opinião.

Módulo 05: 8a aula - Apresentação dos conectores textuais e sua relevância para a construção do artigo de opinião. O professor deve apresentar uma lista de conectores textuais e explicar qual a função deles para a construção de sentidos dos argumentos. Primeira atividade: identificar e destacar a função desses conectores no artigo de opinião "Brasil: um país com racismo, mas sem racistas"10, de Zuenir Ventura. Segunda atividade: Completando o texto "Muito suor, pouca descoberta"11 com os conectores adequados.

Módulo 06: Identificar as estratégias usadas pelos autores para expor sua opinião e convencer os leitores, especialmente, a exemplificação; Perceber que, além da voz do autor, existe, nos artigos de opinião, um funcionamento dialógico, a presença de outras vozes. Atividade 01: Leitura do artigo de opinião "Contra o racismo nada de bananas, nada de macacos, por favor!"12, de Douglas Belchior. Encontrar no texto a questão polêmica, o posicionamento do autor, as várias vozes presentes no texto e justificar o uso das vozes. Atividade 02: Retomar os artigos lidos anteriormente e em grupo identificar as vozes presentes em cada um deles. 
Módulo 07: 10a aula - Sistematizar o conhecimento sobre o gênero; produzir coletivamente um artigo de opinião. Enumerar no quadro a estrutura básica de um artigo de opinião.

1- apresentação da questão polêmica; 2- posição do autor; 3- argumentos de sustentação; 4- contra-argumentos; 5- retomada da posição assumida; 6conclusão.

Pesquisar previamente sobre o tema escolhido. Em seguida, fazer um breve debate com o posicionamento favorável e contrário, (argumentos de sustentação, contra-argumentos) e anotar em cartaz. Por fim, produzir coletivamente um artigo de opinião na lousa, observando todos os aspectos do artigo de opinião.

\section{- Quarto momento - Produção Final}

Primeiramente solicitamos aos alunos que fizessem uma análise da produção inicial por meio do cartaz e de uma ficha de autoavaliação. Em seguida os alunos retomaram a pesquisa sobre o tema preconceito racial no futebol. Posteriormente, explicamos os procedimentos de reescrita para que os alunos refizessem a primeira produção, considerando as condições de produção, o que resultou, após a revisão pelo professor, na produção final. Finalizadas todas as etapas constitutivas desta sequência didática, os textos foram publicados no mural da escola.

\section{Análise da aplicação da sequência didática}

Para analisarmos a sequência didática do gênero artigo de opinião por nós elaborada e aplicada, primeiramente, procuramos observar se ela atingiu o objetivo de ajudar o aluno a dominar o gênero em questão, ampliando seus conhecimentos sobre a argumentação. Para tanto, analisamos cada etapa elencada, por meio de nossos registros, e verificamos se elas buscaram ampliar os conhecimentos que os estudantes já possuíam sobre o gênero, explorando as práticas de oralidade, leitura e, principalmente, de produção escrita conforme propôs o objetivo de cada aula.

$\mathrm{Na}$ apresentação da situação, os alunos tiveram o contato inicial com o gênero artigo de opinião e conheceram o projeto de trabalho com o referido gênero, o que foi relevante para promover uma aproximação entre o aluno e o gênero eleito. Utilizamos a produção inicial como diagnóstico do conhecimento dos alunos sobre o gênero, sendo que a maioria deles desconhecia a estrutura e finalidade do gênero artigo de opinião. $O$ cartaz produzido gradativamente com as informações aprendidas durante os módulos nos auxiliou a perceber a evolução progressiva dos alunos no tocante aos conhecimentos sobre o gênero. Ademais, verificamos que o desenvolvimento da produção coletiva é de suma importância para a aprendizagem do gênero, tendo em vista que por meio desta etapa os alunos se apropriam dos conhecimentos adquiridos nos módulos anteriores, motivo pelo qual consideramos a produção coletiva um dos módulos mais importantes de uma sequência didática, sendo essencial para a ampliação dos conhecimentos dos alunos. Por fim, os alunos refizeram sua produção inicial, inserindo os conhecimentos adquiridos durante as outras etapas. Assim, pudemos fazer a comparação da produção inicial com a produção final dos alunos, verificando se houve uma evolução no tocante aos conhecimentos do gênero e no desenvolvimento da argumentação destes alunos. 
Em suma, após analisarmos os 60 textos produzidos, cumpre ressaltar que a experiência ora relatada, alcançou os seguintes resultados: 39 alunos (65\%) conseguiram atingir os objetivos propostos, evoluindo consideravelmente no decorrer do processo e produzindo artigos de opinião de boa qualidade, utilizando uma argumentação satisfatória. 15 alunos (25\%) atingiram parcialmente os objetivos, tendo em vista que houve uma evolução regular em sua escrita e em sua argumentação. E somente 6 alunos (10\%) - não atingiram os objetivos da proposta da sequência didática, todavia há que se observar que estes alunos não participaram gradativamente das atividades propostas, pelo fato de serem alunos infrequentes. Portanto, consideramos o resultado satisfatório devido à evolução progressiva da maioria dos alunos.

\section{Considerações finais}

Sabemos que a leitura e a produção textual oral e escrita são atividades fundamentais para a inserção do indivíduo no mundo sociocultural em que vivemos. Por serem habilidades imprescindíveis para se acompanhar a evolução contínua do conhecimento e seus usos em situações de práticas discursivas é que elaboramos este estudo, buscando confirmar a essencialidade de se adotar um ensino de linguagem pautado em gêneros e na argumentação.

Propusemos trabalhar com o gênero artigo de opinião pelo fato de este ser um gênero, a partir do qual o autor expressa seu posicionamento sobre um tema polêmico e atual. Assim, por intermédio do referido gênero é possível explorar a argumentação do aluno, focando na persuasão do leitor. A apropriação desse gênero pode, portanto, possibilitar ao aluno o exercício da cidadania por meio da linguagem com seus usos sociais e práticas discursivas.

Apresentamos sinteticamente uma sequência didática por nós elaborada e aplicada, pautada nos ensinamentos de Dolz, Noverraz e Schneuwly (2004), como pressupostos metodológicos para a produção de artigos de opinião e organizamos em torno deste gênero um rol de atividades sistemáticas, com o intuito de abordar esse gênero em suas diversas possibilidades de uso. Após a aplicação da sequência didática, fizemos a análise das etapas constituintes desse procedimento. Por isso, consideramos a produção coletiva uma das etapas mais relevantes da sequência didática, em virtude de termos presenciado, in loco, que as dúvidas relativas ao gênero foram solucionadas neste momento, o que possibilitou uma a apropriação efetiva deste gênero.

Entendemos que todos os momentos da sequência didática convergem para o mesmo ponto: a refaç̧ão eficaz da primeira produção. Nessa fase é que percebemos que, para alcançarmos o desenvolvimento eficaz do procedimento da sequência, é necessário que observemos a evolução dos alunos durante todo o percurso da sequência. Em virtude do exposto, acreditamos que o referido trabalho de produção textual pautado na metodologia de sequências didáticas não apresentou um resultado ideal, pois não atingimos nossos objetivos integralmente. Contudo, obteve um resultado satisfatório no que tange à evolução progressiva da escrita e da argumentação dos alunos.

Acreditamos que esta proposta possa auxiliar os professores do Ensino opinião, em sala de aula. 


\title{
The didactic sequence as an education procedure for opinion article genre
}

\begin{abstract}
This article presents and analyses a work proposal for the opinion article, it has been applied in the Secondary School classrooms. We established a discussion of some themes that conect with this search interests, namely: argumentation and education, opinion article genrer and didactic sequences. Considering the interaction between these themes and, according to the assumptions of Dolz, Noverraz and Schneuwly (2004), mainly, we developed a proposal for the teaching of opinion article genre, with the goal of bringing the student to take ownership of this genre and, consequently, develop their linguistic and discursive skills. Through this proposal we relate theory and teaching practice in order to support the work of the Portuguese language teachers, when the goal is to teach students to produce genres. We believe that this work can bridge the gap between what is taught and what the student uses in social practices.

KEYWORDS: Genres. Argumentation. Didactic sequences. Opinion article.
\end{abstract}




\section{NOTAS}

1 Embora, nos agrupamentos de gêneros propostos por Schneuwly e Dolz (2004) esse gênero esteja nomeado como texto de opinião, adotamos neste estudo a nomenclatura artigo de opinião, tendo em vista ser esta a nomenclatura adotada pelo Currículo Referência da Rede Estadual de Goiás, que elenca esse gênero para ser trabalhado no terceiro bimestre letivo do 9o ano do Ensino Fundamental. Assim, como somos professoras dessa rede estadual, adequamos a sequência didática à nossa realidade.

2 Posicionamento baseado nos agrupamentos de gêneros propostos por Schneuwly e Dolz (2004), ao tratarem do texto de opinião.

3 Vídeo disponível em: <http://www.youtube.com/watch?v=vVxRleCAquE> Acesso em: 25 de out 2014.

4 Entrevista disponível em:<https://www.youtube.com/watch?v=716bF89HFMo $>$ Acesso em: 26 de out 2014.

5 Texto disponível em: http://www.portaleducacao.com.br/psicologia/artigos/20578/as-escolhas-davida\#ixzz35PuAHtbU. Acesso em: 03 de nov de 2014.

6 Texto disponível em: http:Português linguagens: volume 1 / William Roberto/Thereza CocharMagalhães. _ 7. ed. Reform. _ São Paulo: Saraiva 2010. Acesso em: 05 de nov 2014.

7 Texto disponível em:

http:http://professorlfg.jusbrasil.com.br/artigos/118053965/banana-para-oracismo. Acesso em: 05 de nov 2014.

8 Texto disponível em http://www.administradores.com.br/artigos/negocios/asescolhas-de-uma-vida-pedro-bial/42289/. Acesso em: 07 de nov 2014.

9 Todas as figuras foram retiradas do Google imagens.

9 Texto disponível em http://oglobo.globo.com/pais/noblat/posts/2013/01/26/brasil-um-pais-comracismo-mas-sem-racistas-por-zuenir-ventura-483943.asp. Acesso em: 12 novembro 2014. coesao-coerencia.htm (Exercício de número 2). Acesso em: 12 novembro 2014. 
11 Texto disponível em:

http://negrobelchior.cartacapital.com.br/2014/04/28/contra-o-racismo-nada-debananas-por-favor/. Acesso em: 17 novembro 2014.

\section{REFERÊNCIAS}

ABREU, A. S. A Arte de Argumentar: Gerenciando Razão e Emoção. 8. ed. São Paulo: Ateliê Editorial, 2009.

BAKHTIN, M. Os gêneros do discurso. In: Estética da Criação Verbal. 4. ed .São Paulo: Martins Fontes, 2003, p. 262-306.

BOFF, O. M. B.; KÖCHE, V. S.; MARINELLO, A. F. O gênero textual artigo de opinião: um meio de interação. ReVEL. Vol. 7, n. 13, 2009. Disponível em: <www.revel.inf.br>. Acesso em: 17 de ago de 2013.

BRÄKLING , K. L. Trabalhando com o artigo de opinião: Re-visitando o eu no exercício da (re) significação da palavra do outro . In: ROJO, R. (Org.). A prática de linguagem em sala de aula: praticando os PCN's. Campinas, SP: Mercado de Letras, 2000, p. 221-247.

BRASIL. Secretaria de Educação Fundamental. Parâmetros curriculares nacionais: terceiro e quarto ciclos do ensino fundamental: língua portuguesa/ Secretaria de Educação Fundamental. Brasília: MEC/SEF, 1998.

CUNHA, D. A.C. O funcionamento dialógico em notícias e artigos de opinião. In: DIONÍSIO, Â. P.; MACHADO, A. R.; BEZERRA, M. A. (Org.). Gêneros textuais e ensino. São Paulo: Parábola, 2010.

DIAS, E.; et al. Gêneros textuais e (ou) gêneros discursivos: uma questão de nomenclatura? Interações. Portugal, v.7, n. 19, p. 142-155, 2011. Disponível em $<$ http://revistas.rcaap.pt/interaccoes/article/viewFile/475/429 $>$. Acesso em 12 de ago 2014.

DIAS, A. V. M. Hipercontos Multissemióticos. In: ROJO, R; MOURA, E. (Org.). Multiletramentos na escola. São Paulo: Parábola, 2012, p. 95-122.

DOLZ, J. ; NOVERRAZ, M.; SCHNEUWLY, B. Sequências didáticas para o oral e a escrita: apresentação de um procedimento. In: SCHNEUWLY, B; DOLZ, J. Gêneros 
FERREIRA, L. A. Leitura e persuasão: princípios da análise retórica. Contexto: São Paulo, 2010, p. 07-37.

OLBRECHTS-TYTECA, L.; PERELMAN, C. Tratado da Argumentação: a nova retórica. Trad. Maria Ermantina de Almeida Prado Galvão. São Paulo: Martins Fontes, 2005.

RODRIGUES, R. H. R. Os gêneros do discurso na perspectiva dialógica da linguagem: a abordagem de Bakhtin. In: MEURER, J.L.; BONINI, A.; MOTTA-ROTH, D,; (Orgs) Gêneros, Teorias, métodos, debates. São Paulo: Parábola Editorial, 2005, p. 152-183.

ROJO, R. Gêneros do discurso e gêneros textuais: questões teóricas e aplicadas. In: MEURER, J.L.; BONINI, A.; MOTTA-ROTH, D,; (Orgs) Gêneros, Teorias, métodos, debates. São Paulo: Parábola Editorial, 2005, p. 184-207.

SCHNEUWLY, B; DOLZ, J. Gêneros Orais e escritos na escola. Trad. e org. ROJO, Roxane; CORDEIRO, Glaís S. São Paulo: Mercado das Letras, 2004. 
Recebido: 28 abr. 2015

Aprovado: 29 fev. 2016

DOI: $10.3895 /$ rl.v18n22.2911

Como citar: MESQUITA, E.M.C; LEÃO, C.M.E.; SOUZA, D.F.B. As sequências didáticas como um

procedimento de ensino para o gênero artigo de opinião. R. Letras, Curitiba, v. 18, n. 22, p. 55-74, jan./jul.

2016. Disponível em: <https://periodicos.utfpr.edu.br/rl>. Acesso em: XXX.

Direito autoral: Este artigo está licenciado sob os termos da Licença Creative Commons-Atribuição 4.0 Internacional.

(c) (1) 